\title{
EFFECT OF INTRAVENOUS MAGNESIUM SULPHATE ON MORTALITY RATE IN ACUTE ORGANOPHOSPHATE TOXICITY
}

\author{
Tarek Afify ${ }^{a}$, MSc; Usama M. El-Barrany ${ }^{b}$, MD; Hisham Elshikhiby ${ }^{c}$, MD; Mohamed \\ Adly $^{\mathrm{b}}$, MD; Samah Fathy ${ }^{\mathrm{b}}$, MD \\ National Toxicology Center (NECTR) ${ }^{\text {a }}$, Department of Forensic Medicine and Clinical \\ Toxicology ${ }^{\mathrm{b}}$, Department of Pharmacology ${ }^{\mathrm{c}}$, Kasr Al Ainy Faculty of Medicine, Cairo \\ University
}

\begin{abstract}
Background: organophosphates are widely used in agriculture as pesticides, in industry and as household chemicals, allowing many opportunities for acute poisoning, as well as for occupational use. Besides, organophosphates being nerve agents are used in military setting or in terrorist attacks. Fifty years after first use, we still do not know what the optimum treatment for organophosphate toxicity is. Small studies suggest benefit from new treatments such as magnesium sulphate, but much larger trials are needed. The aim of the study was to evaluate the effect of i.v. Magnesium sulphate on mortality rate in acute organophosphate toxicity. Patients and methods: a comparative study in which iv magnesium sulphate was given in a dose of $1 \mathrm{~g} / 6 \mathrm{hrs}$ for $24 \mathrm{hrs}$ to 50 patients acutely intoxicated with organophosphate who are treated with atropine and oximes (group i) and compared to 50 patients who are not given iv magnesium sulphate who are treated with atropine and oximes then mortality rate in the two groups are compared. Results: comparison between the control and the group which took magnesium sulphate showed a statistical significant difference between the 2 groups in the mortality rate $(p<0.05)$. Conclusion: magnesium sulphate decreases mortality rate in acute organophosphate toxicity .such information may in turn guide clinical practice to the use of magnesium sulphate in acute organophosphate toxicity and so more studies should be done to confirm these findings.

Keywords: Magnesium sulphate - acute organophosphate toxicity- - mortality rate

Conflicts of interest: None declared.

*Corresponding author. Department of Forensic Medicine and Clinical Toxicology, Kasr Al Ainy Faculty of Medicine, Cairo University.

E-mail address: afifytarek@gmail.com
\end{abstract}

\section{INTRODUCTION}

Pesticides result in a huge number of intoxications because of their widespread use and easy accessibility especially in the developing world's agricultural communities and constitute high share of intoxicated patients worldwide, since the only life-saving antidotes for ChE-I pesticide poisoning are oxygen and atropine, the most important issue after resuscitation is to decide the need for atropine. The clinical features of cholinergic poisoning are the trigger for the decision to give atropine (Ballantyne and Marrs, 1992).

Organophosphate insecticides irreversibly bind to the enzyme $\mathrm{AChE}$, 
inhibiting its activity and inducing accumulation and prolonged effects of acetylcholine at a variety of neurotransmitter receptors, including sympathetic and parasympathetic ganglionic nicotinic sites, postganglionic cholinergic sympathetic and parasympathetic muscarinic sites, skeletal muscle nicotinic sites, and central nervous system sites (Abdollahi et al., 1995).

Treatment of intoxication with OPs conventionally involves atropine for reduction of muscarinic signs and oximes that increase the rate of hydrolysis of the phosphorylated enzyme acetylcholinesterase (AChE)

\section{(Tafuri and Roberts, 1987).}

Hypomagnesemia and resistance to atropine have been detected in a group of cattle but this finding has not been repeated in either animals or humans (Sungur and Guven, 2001).

The pesticide ingested defines how many patients survive to reach medical attention, how ill they are at admission, effectiveness of oxime therapy, likelihood of recurrent cholinergic crises, or need for respiratory support (Eddleston et al., 2005; Eddleston et al., 2008).

Similarly prognosis in acute poisoning may depend upon many factors like dose and toxicity of the ingested OP (e.g., neurotoxicity potential, half-life, rate of ageing, propoison or poison), and whether dimethyl or diethyl compound (Munidasa et al., 2004).

Thus, any pharmacotherapeutic agent that could prevent or ameliorate the toxicity of OP insecticides could be extremely useful in reducing cost of the treatment and the duration of hospitalization. Of such agents, $\mathrm{MgSO}_{4}$ and clonidine have been found to reduce the toxicity of $\mathrm{OP}$ compounds in animal experiments and non-controlled trials (Richard et al, 2000).

\section{Patients and Methods:}

This unicenter, randomized, prospective control trial was conducted at National Toxicology center (NECTR) - Cairo University. The first patient was enrolled on August 2, 2013, and the last enrolled on October 10, 2014.

The diagnosis of acute OP poisoning was based upon history of oral ingestion of a known OP, presence of characteristic symptoms and signs of muscarinic and nicotinic involvement, and reduced levels of plasma choline esterase.

Patients were excluded from the study if they had concomitant ingestion of other drugs in a suicidal attempt. Patients were divided into two groups and in a systematic sampling, every second eligible patient was chosen to undergo MgSO4 treatment.

We studied 100 patients (56 females, 44 male). Group I consists of fifty patients (25 males, 25 females) received magnesium sulphate ivi ( $1 \mathrm{~g} / 6 \mathrm{hr}$ for first $24 \mathrm{hrs}$ ) beside the routine treatment comprising of gastric lavage, administration of $1 \mathrm{~g} / \mathrm{kg}$ activated charcoal and serial administration of activated charcoal, bathing with water and soap at least three times a day, appropriate bolus and maintenance doses of atropine (the endpoint of atropinization was drying of secretions, flashing, tachycardia and mydriasis), and appropriate doses of obidoxime. Group II consists of fifty patients (31 females, 19 males) received the routine treatment without magnesium sulphate.

The starting dose of obidoxime was 250-500mg IV Additional doses were 
given in a bolus of $250-500 \mathrm{mg}$ IV over 30-60 min every 6-12 hours according to severity of poisoning. The ideal dose of obidoxime was determined by monitoring the clinical condition of the patient and serial assessment of cholinesterase levels over a period of several days.

\section{RESULTS}

Assessment of plasma choline esterase level (BuChE) levels spectrophotometrically in both groups showed no statistically significant difference between group I and group II in plasma choline esterase level on admission ( $p>0.05)$ (Table 1).

Table (1): Comparison between plasma choline esterase (BuChE) level on admission between group I and group II.

\begin{tabular}{|c|c|c|c|}
\hline & $\begin{array}{l}\text { Group I }\left(\mathrm{MgSO}_{4}\right. \\
\text { given) }\end{array}$ & $\begin{array}{ll}\text { Group II } & \text { MgSO }_{4} \\
\text { not given }) & \\
\end{array}$ & $P$ value \\
\hline On admission & 1863 & 1473 & 0.168 \\
\hline
\end{tabular}

*BuChE: Butyryl cholinesterase

Assessment of mortality rate in between those who received $\mathrm{MgSO}_{4}$ and those who didn't, as mortality rate in group I patients is $4 \%$ and mortality rate in group II patients is $24 \%$ which is statistically significant $(p<0.05)$ (Table 2, Figure 1).

Table (2): Comparison between plasma choline esterase (BuChE) level on admission between group I and group II

\begin{tabular}{|c|c|c|c|c|c|}
\hline \multirow{2}{*}{ Mortality } & \multicolumn{2}{|c|}{ Receiving $M g(n=50)$} & \multicolumn{2}{|c|}{ Not receiving $M g(n=50)$} & \multirow[t]{2}{*}{$P$ value } \\
\hline & $\mathbf{N}$ & $\%$ & $\mathbf{N}$ & $\%$ & \\
\hline Non-survivors & 2 & 4.0 & 12 & 24.0 & $\begin{array}{l}\text { P value } \\
0.008\end{array}$ \\
\hline Survivors & 48 & 96.0 & 38 & 76.0 & $\mathbf{S}$ \\
\hline
\end{tabular}

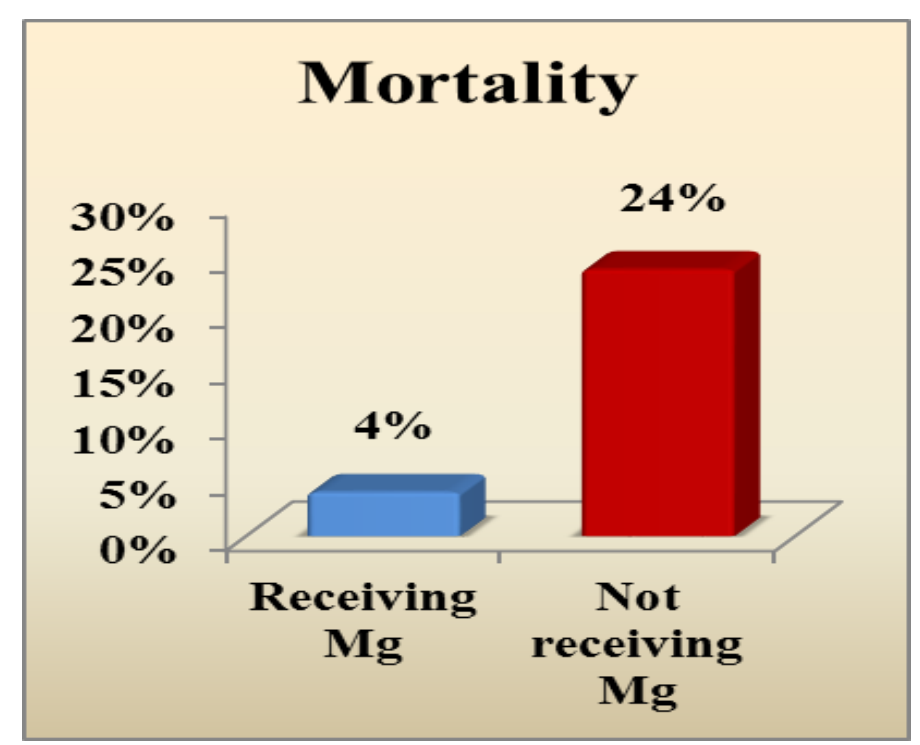

Figure (1): Comparison between mortality rate in Group I and Group II *Mg: Magnesium Sulphate 


\section{DISCUSSION}

Hypomagnesemia and resistance to atropine have been detected in a group of cattle but this finding has not been repeated in either animals or humans (Sungur and Guven, 2001).

In our study, on admission there was no statistical difference between the 2 groups in $\mathrm{BuChE}$ activity in plasma and this is consistent with Pajoumand et al., 2004 and Basher et al., 2013.

Our findings show that $\mathrm{MgSO} 4$ therapy reduced mortality rate from $24 \%$ in the control study to $4 \%$ and this result is consistent with Pajoumand et al., 2004 and Basher et al., 2013.

\section{CONCLUSIONS}

It is recommended to infuse magnesium sulphate in a dose of $1 \mathrm{~g} / 6$ hrs in acute organophosphate toxicity to reduce mortality rate.

Adequate follow up and monitoring of either regimens administered and adequate titration to symptoms may play an important role for clinical improvement of intoxicated patients.

There is other many factors that affect the improvement of the clinical presentations of CHE-I poisoning besides the treatment regimen as type of organophosphate and delay before medical management.

\section{REFERENCES}

Abdollahi M, Jafari A, Jalali N, Balai MM, Kebriaeezadeh $A$ and Nikfar S. (1995): A new approach to the efficacy of oximes in the management of acute organophosphate poisoning. J Med Sci; 20: 105 -109.
Ballantyne B. and Marrs T. (1992): Overview of the biological and clinical aspects of organophosphates and carbamates. In Clinical and experimental toxicology of organophosphates and carbamates. Edited by Ballantyne B, Marrs TC. Oxford: Butterworth heinemann; 3-14.

Basher A, Rahman SH, Ghose A. et al. (2013): Phase II study of magnesium sulfate in acute organophosphate pesticide poisoning. Clin Toxicol.; 51(1):3540.

Eddleston M, Eyer P, Worek F et al. (2005): Differences between organophosphorus insecticides in human self-poisoning: a prospective cohort study. Lancet; 366: 1452-159.

Eddleston M, Buckley N, and Eyer P (2008): Medical Management of Acute Organophosphorus Pesticide Self-Poisoning. Lancet; 371(9612): 597-607.

Munidasa U., Gawarammana I, Kulratne S et al. (2004): Survival Pattern of Patients with Acute Organophosphate Poisoning Receiving Intensive Care. J Toxicol Clin Toxicol.; 42: 343-347.

Pajoumand A, Shadnia S, Rezaie A et al. (2004): Benefits of magnesium sulfate in the management of acute human poisoning by organophosphorus insecticides. Hum Exp Toxicol.; 23:565-569.

Tafuri J and Roberts J. (1987): Organophosphate poisoning. Ann Emerg Med.; 16: 193 -202. 
تأثير كبريتات المغتيسيوم عن طريق الوريد على العبدل الوفلى الوفاة في سمية عضوي الفوسفات

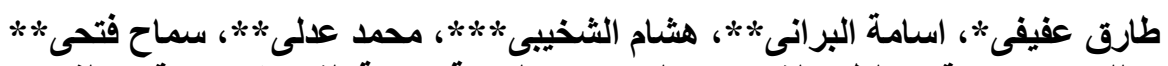

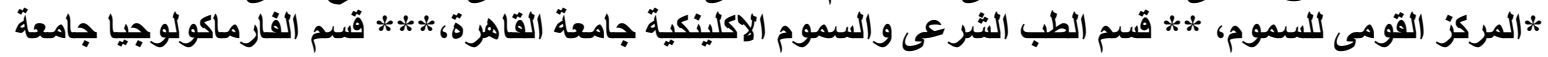
القاهرة

تستخدم الفوسفات العضوي على نطاق واسع في الزر اعة كمبيدات للآفات ، وفي الصناعة ولاتهة وكيماويات

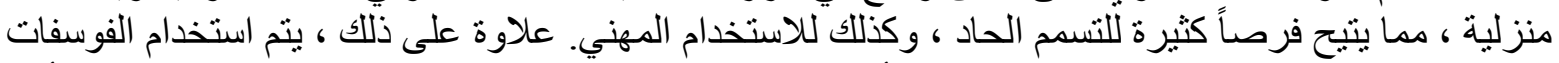

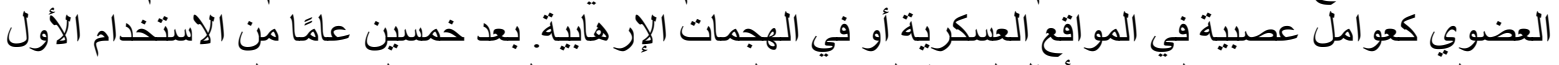

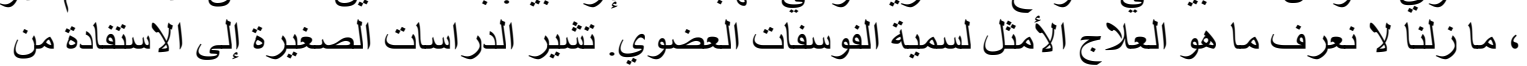

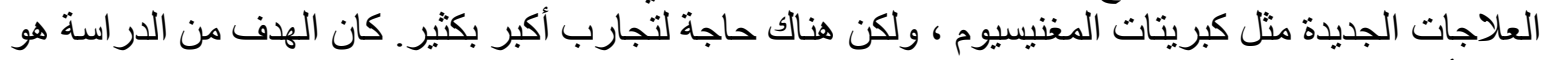

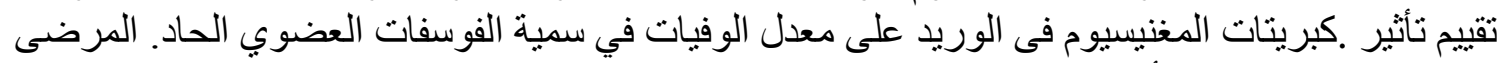

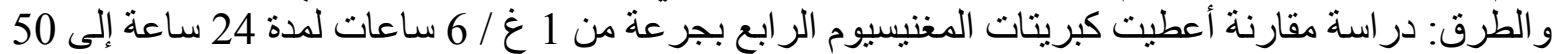

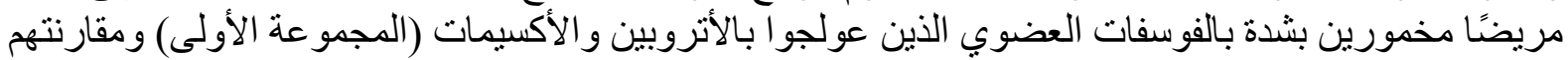

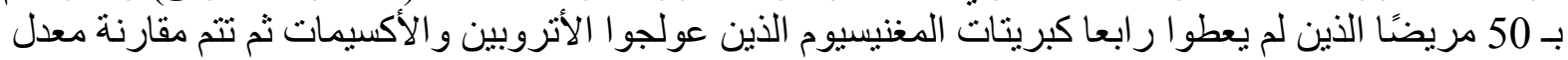

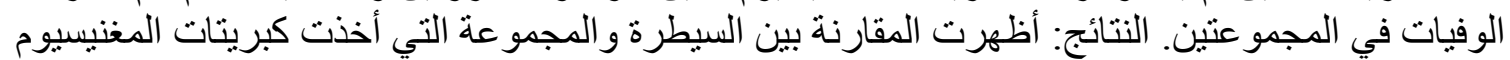

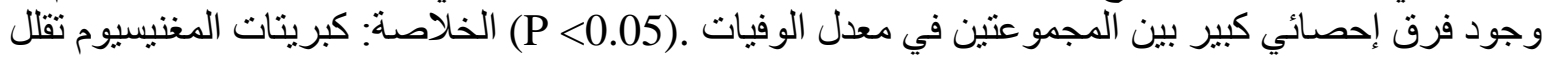

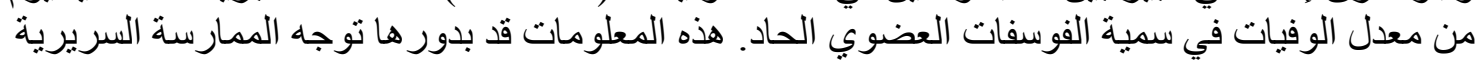

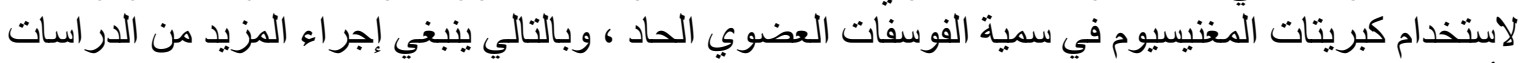
لتأكيد هذه النتائج. الكلمات المفتاحية: سلفات المغنيزيوم ـ سمية الفوسفات العضوي الحاد ـ معدل الوفيات 